\title{
ALTERAÇÕES NOS PERFIS BIOQUÍMICOS HEPÁTICOS E RENAIS DE Didelphis spp. SORORREAGENTES A Leptospira spp. DOS BIOMAS BRASILEIROS CERRADO E CAATINGA
}

\author{
CHANGES IN BIOCHEMICAL PROFILES IN KIDNEY AND LIVER OF \\ Didelphis spp. SEROPOSITIVE TO Leptospira spp. OF BRAZILIAN BIOMES \\ CERRADO AND CAATINGA
}

T. R. SILVA ${ }^{1 *}$, A. F. S. NOGUEIRA ${ }^{1}$, N. R. N. CRUZ ${ }^{1}$, R. F. SANTOS ${ }^{1}$, L. A. MATHIAS ${ }^{1}$, A. E. SANTANA ${ }^{1}$

\begin{abstract}
RESUMO
O objetivo deste estudo foi avaliar os perfis bioquímicos hepáticos e renais de Didelphis spp. (gambás) de vida livre sororreagentes à Leptospira spp., provenientes dos biomas brasileiros cerrado e caatinga. Foram colhidas amostras de sangue de nove animais de vida livre para realização do teste de soroaglutinação microscópica (SAM) e das análises bioquímicas de aspartato amino-transferase (AST), alanino aminotransferase (ALT), gama-glutamil transferase (GGT), ureia (UV), creatinina, fosfatase alcalina (F.A.), albumina, bilirrubina total, direta e indireta. Os resultados expressos como média \pm desvio padrão foram para Didelphis aurita: creatinina $(0,87 \pm 0,13 \mathrm{mg} / \mathrm{dL})$, ALT $(76,83 \pm 32,02 \mathrm{U} / \mathrm{mL})$, AST $(103,00 \pm 16,82$ $\mathrm{U} / \mathrm{mL})$, ureia $(31,33 \pm 12,34 \mathrm{mg} / \mathrm{dL})$, F.A. $(65,57 \pm 9,57 \mathrm{U} / \mathrm{L})$, GGT $(25,50 \pm 4,41 \mathrm{U} / \mathrm{L})$, bilirrubina total $(0,61 \pm 0,22 \mathrm{mg} / \mathrm{dL})$, bilirrubina direta $(0,21 \pm 0,08 \mathrm{mg} / \mathrm{dL})$, bilirrubina indireta $(0,40 \pm 0,14 \mathrm{mg} / \mathrm{dL})$ e albumina $(2,01 \pm 0,02 \mathrm{~g} / \mathrm{dL})$. Para $D$. albiventris: creatinina $(1,39 \pm 0,18 \mathrm{mg} / \mathrm{dL})$, ALT $(51,33 \pm 10,73 \mathrm{U} / \mathrm{mL})$, AST $(97,42 \pm 29,53 \mathrm{U} / \mathrm{mL})$, ureia $(34,40 \pm 5,68 \mathrm{mg} / \mathrm{dL})$, F.A. $(59,70 \pm 28,36 \mathrm{U} / \mathrm{L})$, GGT $(30,60 \pm 10,81 \mathrm{U} / \mathrm{L})$, bilirrubina total $(0,62 \pm 0,50 \mathrm{mg} / \mathrm{dL})$, bilirrubina direta $(0,35 \pm 0,40 \mathrm{mg} / \mathrm{dL})$, bilirrubina indireta $(0,26 \pm 0,19$ $\mathrm{mg} / \mathrm{dL})$ e albumina $(2,26 \pm 0,20 \mathrm{~g} / \mathrm{dL})$. Para $D$. marsupialis os valores foram: creatinina $(1,14 \mathrm{mg} / \mathrm{dL})$, ALT $(94,28 \mathrm{U} / \mathrm{mL})$, AST $(110,00 \mathrm{U} / \mathrm{mL})$, ureia $(23,00 \mathrm{mg} / \mathrm{dL})$, F.A. $(49,75 \mathrm{U} / \mathrm{L})$, GGT $(30,60 \mathrm{U} / \mathrm{L})$, bilirrubina total $(1,99 \mathrm{mg} / \mathrm{dL})$, bilirrubina direta $(0,14 \mathrm{mg} / \mathrm{dL})$, bilirrubina indireta $(1,85 \mathrm{mg} / \mathrm{dL})$ e albumina $(2,09 \mathrm{~g} / \mathrm{dL})$.Todos os animais apresentaram alterações em pelo menos um parâmetro. Não se pode atribuir as alterações exclusivamente à infecção, pois fatores como clima, alimentação, estação do ano e infecção por outros agentes também podem causar variações, porém a análise do perfil bioquímico é importante para avaliar clinicamente o estado de saúde do animal e para o acompanhamento terapêutico. Dados na literatura de parâmetros bioquímicos são escassos, incompletos e até ausentes para algumas espécies de gambás. São necessários mais estudos sobre esta doença nos animais selvagens, contribuindo assim com projetos de conservação, manejo, prevenção e controle desta zoonose.
\end{abstract}

PALAVRAS-CHAVE: LEPTOSPIROSE. ANÁLISES BIOQUÍMICAS. GAMBÁS.

AGRADECIMENTOS: Fundação de amparo à pesquisa do Estado de São Paulo (Fapesp).

ÁREA TEMÁTICA: Doenças infecciosas. 